\title{
Substance Use Disorders and the American Nurses Association Code of Ethics for Nurses
}

Marie Manthey, MNA, FRCN, FAAN

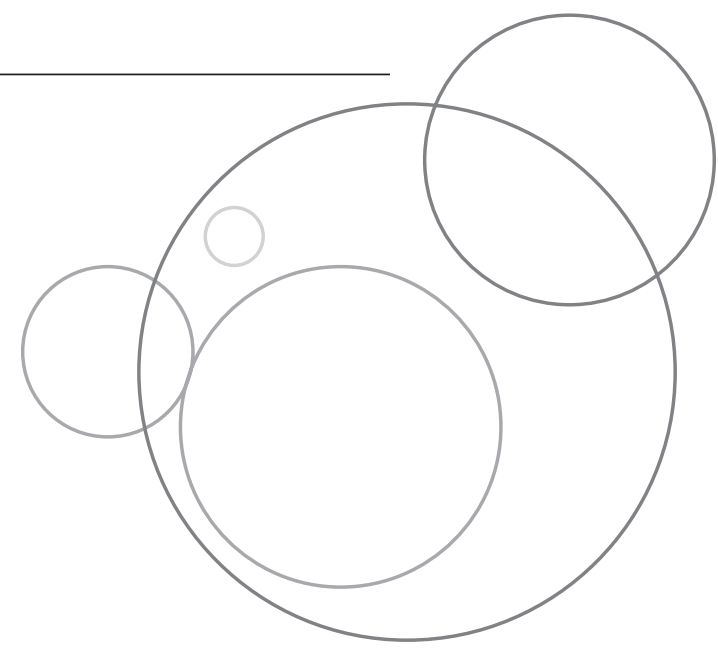

Substance use disorder is a serious problem in nursing that is often invisible and not well understood or well handled. It tears at the social contract between nursing and society and disrupts the trust so essential to that contract. The American Nurses Association Code of Ethics contains clear language about a nurse's duty to take action to protect patients and to ensure the impaired nurse gets assistance. Specific interpretive statements provide useful guidance in dealing with this problem.

Keywords: substance use disorder; peer support networks; ANA Code of Ethics with Interpretive Statements; nursing's contract with society

$\mathbf{S}$ ubstance use disorder (SUD) is a serious problem in nursing that is often invisible and not well understood or well handled. It tears at the social contract between nursing and society and disrupts the trust so essential to that contract. The American Nurses Association (ANA) Code of Ethics contains clear language about a nurse's duty to take action to protect patients and ensure the impaired nurse gets assistance. Specific interpretive statements provide useful guidance in dealing with this problem. Nurses are exposed to multiple risk factors for addictions, including highly stressful work environments, easy access to addictive drugs, negative attitudes toward patients struggling with addiction, and a strong "conspiracy of silence" that covers up the reality of SUDs. These factors come together in a perfect storm, endangering patient safety and sometimes ending the careers of some of our most engaged nurses.

Historically, chemical dependency and alcoholism have been identified as significant issues for the profession, and while nursing technically recognizes addiction as a disease, in reality, addiction among nurses is more often thought of as a moral failure (Weber, 2017). Despite how serious a problem addiction is in the nursing profession, people entering the field are generally underinformed about the hidden trap that jeopardizes the lives, licenses, and careers of nurses.

There is an unwritten, mostly unspoken, but well-understood covenant between nursing and society, evidenced by nursing's year-after-year selection as the most trustworthy occupation/profession in Gallup's national survey (Nurse.org, 2017). This covenant is easily broken, however, when addiction becomes a factor. Statistically, at least 1 in 10 nurses will acquire a SUD (Thomas \& Siela, 2011). And

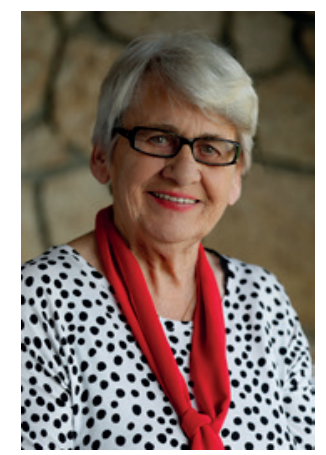

Marie Manthey, MNA, FRCN, FAAN, is President Emeritus of Creative Health Care Management and Founding Editor of Creative Nursing. 
The reality that $10 \%$ of the nursing workforce is either in addiction or in recovery obligates us to articulate a clear professional commitment to preventing substance use disorder through fully articulating the potential risks and outlining an effective response. yet, the conspiracy of silence, coupled with the lack of understanding of risk factors in nursing, has resulted in a failure to create a sound mechanism for protecting society while providing nurses with accessible and timely access to recovery.

The most recent edition of the ANA's Code of Ethics for Nurses with Interpretive Statements American Nurses Association (2015) has the potential to break the silence by clearly pointing out the ethical path to identification and action that each professional nurse has when dealing with the problem of SUDs in the workplace. In a recent issue of American Nurse Today, Weber wrote:

While state boards of nursing enforce laws to regulate practice, our profession's Code of Ethics for Nurses with Interpretive Statements, written and revised by the American Nurses Association (ANA) [over] roughly a century, goes above and beyond the law. It is the non-negotiable ethical standard to which nurses adhere.

That standard places the nurse's first duty to the patient. Provision 3.0 of the Code states, "The nurse promotes, advocates for, and protects the rights, health and safety of the patient." This is a far-reaching provision that encompasses our mandate to protect human research subjects, our authority and responsibility to report adverse events and "near misses," and our individual and joint obligation to both protect patients from impaired nursing practice and to help sick, impaired colleagues get needed treatment while acting to protect them from undue punishment for being sick. (Weber, 2017, p. 42)

Weber accurately points out that the ANA Code of Ethics compels nurses not only to recognize the impairment of fellow nurses, but to help those nurses. Weber goes on to outline how nurses can fulfill this ethical obligation:

A growing body of professional standards affirms that SUD alone is not a moral failing or punishable crime. The Code's interpretive Statement 3.6 states, the nurse's duty is to take action to protect patients and to ensure that the impaired individual receives assistance. This process begins with consulting supervisory personnel, followed by approaching the individual in a clear and supportive manner and by helping the individual access appropriate resources. The nurse should extend compassion and caring to colleagues throughout the process of identification, remediation, and recovery. Care must also be taken in identifying any impairment in one's own practice and seeking immediate assistance. (Weber, 2017, p. 42)

Dr. Weber applies the clear language of the Code of Ethics to the complex problem of SUD in nursing. The new version of the Code of Ethics is an important linchpin in the educational mandate now being recognized for teaching nurses about the high risks and dire consequences of addiction in nursing. It is not enough to teach student nurses about pain management and the dangers of opioid use. The reality that $10 \%$ of the nursing workforce is either in addiction or in recovery (Thomas \& Siela, 2011) obligates us as a profession to articulate a clear professional commitment to preventing SUD through fully articulating the potential risks and outlining an effective response to SUD that protects patient safety while supporting nurses, including peer support networks, in seeking treatment and entering into successful recovery.

It is fortunate for the profession that the ANA Code of Ethics provides clearly stated ethical principles which enable nurses to take appropriate actions when they are in situations in which a colleague is impaired. The problem of SUD among nurses is too large already, and with the increased acuity, complexity, and physical 
demands nurses face today, it is poised to grow rather than shrink. SUD will probably always be with us. We are fortunate to have clear ethical principles to guide us as we reclaim committed nurses from the grip of addiction and empower them to return to practice renewed, grateful, and poised to help others to avoid SUDs.

\section{REFERENCES}

American Nurses Association. (2015). Code of ethics for nurses with interpretive statements. Silver Spring, MD: Author.

Nurse.org. (2017). Nurses ranked \#1 most ethical profession in 2017 Gallup poll. Retrieved from https:/ / nurse.org/articles/gallup-ethical-standards-poll-nurses-rank-highest/

Thomas, C. M., \& Siela, D. (2011). The impaired nurse: Would you know what to do if you suspected substance abuse? American Nurse Today, 6(8).

Weber, E. (2017). What to do when a colleague is impaired. American Nurse Today, 12(9). Retrieved from https://www.americannursetoday.com/wp-content/uploads/2017/ 09/September-2017-Frontline-FINAL.pdf

We are fortunate

to have clear eth-

ical principles to

guide us as we

reclaim commit-

ted nurses from

the grip of ad-

diction and em-

power them to

return to practice renewed, grateful, and poised

to help others to avoid substance use disorders.

Correspondence regarding this article should be directed to Marie Manthey, MNA, FRCN, FAAN, at mmanthey@ chcm.com 